\title{
Simplification of literary and scientific texts to improve reading fluency and comprehension in beginning readers of French
}

\author{
Ludivine Javourey-Drevet ${ }^{1,2,3} \mathbb{D}$, Stéphane Dufau ${ }^{1} \mathbb{D}$, Thomas François ${ }^{4} \mathbb{D}$, Núria Gala ${ }^{5}$, \\ Jacques Ginestié ${ }^{2}$ (D) and Johannes C. Ziegler ${ }^{1, *}$ (D) \\ ${ }^{1}$ Aix-Marseille Univ, CNRS, Laboratoire de Psychologie Cognitive (UMR 7290), Marseille, France, \\ ${ }^{2}$ Aix-Marseille Univ, Apprentissage, Didactique, Évaluation, Formation (EA 4671), Marseille, France, \\ ${ }^{3}$ Univ Lille, CNRS, SCALab - Sciences Cognitives et Sciences Affectives, (UMR 9193), Lille, France, \\ ${ }^{4}$ Université catholique de Louvain, ILC, CENTAL, Louvain-La-Neuve, Belgium and ${ }^{5}$ Aix-Marseille Univ, \\ CNRS, Laboratoire Parole et Langage (UMR 7309), Aix-en-Provence, France \\ ${ }^{*}$ Corresponding author. Email: Johannes.Ziegler@univ-amu.fr
}

(Received 2 April 2020; revised 4 December 2021; accepted 7 December 2021; first published online 31 January 2022)

\begin{abstract}
Reading comprehension and fluency are crucial for successful academic learning and achievement. Yet, a rather large percentage of children still have enormous difficulties in understanding a written text at the end of primary school. In this context, the aim of our study was to investigate whether text simplification, a process of reducing text complexity while keeping its meaning unchanged, can improve reading fluency and comprehension for children learning to read. Furthermore, we were interested in finding out whether some readers would benefit more than others from text simplification as a function of their cognitive and language profile. To address these issues, we developed an iBook application for iPads, which allowed us to present normal and simplified versions of informative and narrative texts to 165 children in grade 2. Reading fluency was measured for each sentence, and text comprehension was measured for each text using multiple-choice questions. The results showed that both reading fluency and reading comprehension were significantly better for simplified than for normal texts. Results showed that poor readers and children with weaker cognitive skills (nonverbal intelligence, memory) benefitted to a greater extent from simplification than good readers and children with somewhat stronger cognitive skills.
\end{abstract}

Keywords: Text simplification; fluency; reading comprehension; readability; textual variability

Reading fluency and text comprehension are fundamental for school achievement across a variety of disciplines. Yet, international comparisons, such as PIRLS, suggest that 10 out of 50 countries, in which reading comprehension was tested with grade 4 children, show alarmingly low average scores (Mullis et al., 2017). The

(C) The Author(s), 2022. Published by Cambridge University Press. This is an Open Access article, distributed under the terms of the Creative Commons Attribution licence (http://creativecommons.org/licenses/by/4.0/), which permits unrestricted re-use, distribution and reproduction, provided the original article is properly cited. 
situation seems particularly problematic in France, which ranked $34^{\text {th }}$ out of 50 . Indeed, $6 \%$ of the students in France versus $4 \%$ in Europe have a standard score below 400, which is taken as an indicator that they do not master elementary reading and comprehension skills (Mullis et al., 2017). Since the first PIRLS evaluation in 2001, performance in reading comprehension of French students has dropped year after year, especially for complex reading comprehension skills (e.g., inference) and informative texts (e.g., scientific or documentary texts). In the recent national evaluations, in which 780,000 grade 2 students in France were tested on reading fluency and reading comprehension (Andreu et al., 2019), it was also found that $22 \%$ of the students had problems in understanding a written sentence and that $30 \%$ read less than 30 words per minute. At that reading speed, it would take a child more than $9 \mathrm{hr}$ to read Saint Exupery's The Little Prince compared to a skilled reader who is able to read the novel in about $1 \mathrm{hr}^{1}$. In this present article, we explore to what extent text simplification might be a viable tool for increasing reading fluency and text comprehension in normal readers who attend regular primary schools (grade 2) in France.

\section{What does it take to understand a written text?}

According to the most influential theory, the simple view of reading (Gough \& Tunmer, 1986; Hoover \& Gough, 1990), reading comprehension (R) is simply the product of word identification or decoding ability (D) and oral comprehension (C), which leads to the straightforward equation $\mathrm{R}=\mathrm{D} \times \mathrm{C}$. Although it has been questioned to what extent the components are really independent (Ouellette \& Beers, 2010; Tunmer \& Chapman, 2012) and whether one would need to take fluency (Adlof et al., 2006; Silverman et al., 2013) or vocabulary into account (Tunmer \& Chapman, 2012), this simple equation has been confirmed in a variety of languages (Johnston \& Kirby, 2006; Joshi \& Aaron, 2000; Kirby \& Savage, 2008) and grade levels (Kershaw \& Schatschneider, 2012; Tilstra et al., 2009). In a recent 5-year longitudinal study with Norwegian grade 2 readers $(\mathrm{N}=198)$, Lervåg and colleagues (2018) have shown that one can explain $96 \%$ of the variance in reading comprehension growth by carefully estimating decoding and oral comprehension skills (vocabulary, grammar, verbal working memory, and inference skills).

The multiplicative nature of the relationship implies that if word identification is weak $(\mathrm{D} \rightarrow 0)$, written comprehension will be impaired even if oral comprehension were good. This is the case for children with dyslexia who exhibit difficulties in understanding a written text despite fairly normal oral comprehension (Bishop \& Snowling, 2004; Perry, Zorzi \& Ziegler, 2019; Ziegler, Perry \& Zorzi, 2019). The equation further implies that if oral comprehension is deficient $(C \rightarrow 0)$, written comprehension is impaired despite good word identification skills. This is the case for children with poor vocabulary or poor language skills, who also exhibit deficits in reading comprehension despite the fact that might correctly decode all of the words in a text (Bishop \& Snowling, 2004; Perry et al., 2019; Wauters et al., 2006; Ziegler et al., 2019). Indeed, in fluent skilled readers who have fully automatized word identification $(D \rightarrow 1)$, written comprehension is almost entirely explained by oral comprehension (Gentaz et al., 2015). 
The second theory that is highly relevant in the context of text simplification is the lexical quality hypothesis (Perfetti, 2007). Lexical quality refers to the extent to which the reader's knowledge of a given word represents the word's form and meaning constituents and knowledge of word use that combines meaning with pragmatic features. The lexical quality theory implies that variation in the quality of lexical representations, including both form and meaning knowledge, lead to variation in reading skill, including comprehension. The consequences of lexical quality can be seen in processing speed at the lexical level, and, especially important, in comprehension. At the extreme end, low-quality representations lead to specific word-related problems in comprehension.

This rapid review of the literature shows that in order to increase text comprehension, one can influence the ease of word identification (decoding), the quality of lexical representations, or the quality of oral comprehension. While changing oral comprehension skills and the quality of lexical representations requires early intensive intervention (Bowyer-Crane et al., 2008), word identification can be facilitated "on the fly" by text simplification (see below). This was the approach chosen in the present study. By virtue of the equation presented above, if word identification is made easier, text comprehension should be improved. Similarly, if words with poor lexical quality are replaced by words with better lexical quality, processing speed and comprehension should be improved. Of course, simpler words are also more likely to be in the vocabulary of the child, which is an "oral-language" factor that goes beyond word identification.

\section{Text simplification}

Text simplification can operate at different linguistic levels (lexical, morphosyntactic, and discursive) in order to make texts more readable while preserving their original content (Saggion, 2017). Lexical simplification is concerned with providing access to the ideas with fewer words. Common strategies to carry out lexical simplification are the use of superordinate terms, approximation, synonymy, transfer, circumlocution, and paraphrasing (Blum \& Levenston, 1978). Although simpler words are usually more frequent and shorter, one needs to consider the characteristics of the target population for the definition of simplicity (what may be simple for low-vision patients might not be simple for children with dyslexia or illiterates). Word frequency is the major variable that affects the ease of word recognition (e.g., Coltheart et al., 2001). Syntactic simplification consists in reducing the complexity of syntactic structures by deleting or replacing complex constructions (Brouwers et al., 2014), such as relative or subordinate and coordinate clauses. Discursive simplifications address phenomena, such as sentence reordering, explicitness of coreference chains, or anaphora resolution. Given that pronouns are a source of ambiguity and syntactic complexity (Bormuth, 1966), the replacement of a personal pronoun by a noun reduces the amount of processing inferences a reader has to do in order to link one referring expression to its antecedents (Wilkens \& Todirascu, 2020). Other forms of simplification can also be used to increase the personalization level of texts, reorganize ideas, reduce the density of ideas, or summarize ideas (Clerc \& Kavanagh, 2006). 
Trying to reduce the complexity in texts is not a new idea. For instance, publishers have offered "simplified" editions of classic literature, in which parts of the original texts have been removed to make the texts more accessible to young readers. Although this method shortens the reading material, it does not tackle the problem of simplification of the text itself. To do so, several strategies have been proposed. One possible way is to create a simplified text ex nihilo, that is, to write a text that responds to "simplicity" instructions based on linguistic and textual recommendations. In this case, there is no original text considered as complex or difficult. An example is the collection La Traversée (Weyrich Editions), a collection of short novels specifically written for adult illiterates or weak readers. To create these texts, the writers had to respect a set of specifications, which served as a guide, and they benefited from feedback on their texts from a sample of target readers. Another example is the Colibri collection (Belin Edition), which proposes books that are written for readers with dyslexia following a number of editorial rules. Each book belongs to one of four difficulty levels, which take into account the complexity of French grapheme-to-phoneme correspondences. The stories are accompanied by educational activities to facilitate their reading and check their comprehension.

The second simplification strategy is to transform an original text so that it becomes more accessible to a specific readership. The first emblematic example is Plain Language ${ }^{2}$ which was set up by the American administration in the 70 s in response to the observation that a significant part of the population was not able to understand administrative documents. The guidelines focused on avoiding complicated sentences (administrative jargon and negative sentences) and included stylistic recommendations, such as, using personal pronouns, short paragraphs, and visual layout elements (titles, lists, etc.). Another example is that of encyclopedic texts for children. For example, Vikidia proposes articles with simplified content for young readers, and the Dyscool collection (Nathan Edition) proposes 16 French books where the texts are adapted in various ways. Complex sentences are rewritten with short and simple sentences keeping the standard order (subject-verb-object). Complex or long words are explained or replaced by easier and shorter words. Stylistic figures and characters are made explicit or replaced by easier referents. Finally, for English learners, the Newsela ${ }^{3}$ corpus is composed of 1,911 original news articles, for which professional writers created 4 equivalent versions for different reading levels.

The effects of text simplification on reading speed or comprehension have been investigated in previous studies. For instance, Margarido and colleagues (2008) conducted several experiments on summarization and text simplification for poor readers, more specifically, functionally illiterate readers in Brazil. They used various summaries as the basis of their simplification strategy and showed that each simplification approach had different effects depending on the level of literacy, but that all of them improved text understanding at some level. Gala and Ziegler (2016) investigated the benefits of text simplification for children with dyslexia. They asked 10 children with dyslexia to read aloud the original and manually simplified version of standardized French texts and to answer comprehension questions after each text. The results showed that the simplifications increased reading speed and reduced the number of reading errors (mainly lexical) without a loss of understanding. In a 
similar line of research, Rello and collaborators (2013) found that lexical simplification (i.e., replacing complex words by simpler equivalents) improved both reading speed and comprehension for readers with dyslexia. In an eye-tracking experiment with 23 dyslexics and 23 controls, they compared texts in which words were substituted by shorter and more frequent synonyms. The use of more frequent words allowed participants with dyslexia to read faster, while the use of shorter words allowed them to better understand the text. The beneficial effects of simplification were only present for readers with dyslexia but not for the controls.

Fajardo and colleagues (2013) investigated whether adding cohesive elements of texts such as connectives (e.g., but, in contrast) and high-frequency words would improve inferential comprehension in poor readers with intellectual disability. Neither the addition of high-frequency content words nor connectives produced inferential comprehension improvements. Although the average performance of a reading level-matched control group (typically developing children) was similar to the group of poor readers with intellectual disability, the pattern of interaction between familiarity and type of connectives varied between groups.

These results by Fajardo et al. (2013) suggest that the beneficial effects of text simplification should not be taken for granted. Indeed, simplifying on the basis of overly simplistic criteria (e.g., length of sentences and words) can lead to producing texts that are less comprehensible in terms of logical links (Davison \& Kantor, 1982) or texts whose style is neglected in terms of rhythm, variety of linguistic forms, and coordination and subordination strategies (Selzer, 1981). Also, removing connectives (e.g., therefore, furthermore) has been shown to have a detrimental effect on reading speed and comprehension, especially when texts have a continuous layout (Van Silfhout et al., 2014).

In sum, there is some evidence that text simplification provides a viable tool to increase reading comprehension in special-needs populations, such as illiterate or dyslexic readers (Gala \& Ziegler, 2016; Margarido et al., 2008; Rello et al., 2013; but see Fajardo et al., 2013). It is an open question as to whether text simplification can be useful for normally developing beginning readers and whether there is an additional benefit for those who have weak oral language skills, poor decoding skills, or weak cognitive abilities. To our knowledge, few studies investigated the effects of text simplification on different types of text (but see Fajardo et al., 2013).

\section{Goal of the present study}

The overall goal of our study was to test whether text simplification could improve reading fluency and comprehension for normally developing children learning to read in French and whether the cognitive or language profile of the children would modulate the size of simplification benefits. To address these questions, we manually simplified 10 narrative and 10 scientific texts. Both genres are commonly used in primary school, but their objectives differ. On the one hand, literary texts reflect the world view and the sensitivity of its author. They are not necessarily meant to be useful or instructive. On the other hand, scientific (documentary) texts are descriptive and explanatory with a logical structure based on scientific reasoning. They tend 
to describe a scientific or technological causality. The variables that determine reading comprehension are quite similar for both types of texts (e.g., Best et al., 2008; Liebfreund \& Conradi, 2016). We were interested in comparing simplification for the two kinds of texts because the decline in comprehension scores in French primary students in the PIRLS study was most pronounced for informational texts.

In our study, all children were presented with informational and literary texts either in its original or simplified version (counterbalanced across participants). The texts were embedded in an iBook application for iPads, which allowed us to present texts sentence by sentence ${ }^{4}$. It could be argued that presenting texts sentence by sentence is a simplification on its own. Indeed, it has been shown that presenting texts line by line on electronic devices can improve reading speed and comprehension for struggling readers (Schneps et al., 2013). However, we presented both types of texts (normal and simplified) line by line on an electronic device. Therefore, any difference between normal and simplified texts cannot be explained by this presentation mode.

After reading each sentence, the child had to press an on-screen spacebar to receive the following sentence, which made it possible to estimate an approximate fluency measure by dividing the total reading time (RT) of the sentence by the number of words or characters that made up the sentence. Finally, after the silent reading of each text, children received a set of multiple-choice comprehension questions, which were identical in the original and simplified version of the text. We hypothesized that simplified texts should be read more fluently than original texts. We further hypothesized that the simplified version of a text should obtain higher comprehension scores than the original version. We finally hypothesized that simplification should be more beneficial for poor readers and children with weak oral language skills.

\section{Methods}

\section{Participants}

A total of 165 grade 2 students ( 81 girls and 84 boys) from 9 classes were recruited in 4 different schools located in 3 different towns in the south of France (Sanary sur Mer, Saint Cyr, La Cadière d'Azur). These towns host a suburban population with little immigration and average-to-high socioeconomic status. The departmental school authorities pseudo-randomly selected the schools on the basis of them being fully equipped with connected iPads and the school principals agreeing to participate in the study.

All participants were native speakers of French. Three of them were bilingual (Portuguese, Arabic, and Bulgarian), but there was no reason to discard them from the study. The average age of the students was 92.9 months ( 7.7 years). Ethics approval was obtained from the institutional review board of Aix-Marseille University. The departmental school authorities authorized the study. Parents gave informed written consent. 


\section{Procedure}

The study comprised two phases: (a) an individual testing phase made up of four sessions of $30 \mathrm{~min}$ (see below) whose purpose was to obtain a variety of linguistic, cognitive, and psycholinguistic measures for each participant and (b) a classroom phase, in which children silently and autonomously read the texts on an iPad (from March to June 2017). Each student read 20 texts, 10 were literary texts (5 original and 5 simplified) and 10 were scientific texts ( 5 original and 5 simplified). Each text was only read once by the same student, either in its original or simplified version. Thus, simplification and nature of the text were within-subject manipulations.

After reading a given text, the subjects had to answer a multiple-choice questionnaire (MCQ) designed to measure their comprehension of the text. The MCQ comprised five comprehension questions, each of which had three alternatives (correct, related to the text but incorrect, and unrelated to the text and incorrect). The questions were constructed to avoid reliance on cultural background knowledge. Importantly, the questions were identical in the original and in the simplified versions, and the students could not go back to the text in order to answer them. The order of questions and alternatives was randomized between participants. In order to motivate the students, we implemented the reading tests as a game, in which they could win rewards (stars) proportionally to the amount of correct answers provided. In case of hesitation, the student could change his/her answer before validating it and moving on to the next question.

We implemented the reading tests and the comprehension task on iPads using an iBook template. In general, the texts were presented sentence by sentence. This allowed us to collect RTs per sentence and hence estimate the average reading speed per word. Occasionally, we presented more than one sentence at once if a given sentence was meaningless without the one preceding or following it or in a dialog situation, in which the same character "pronounced" two sentences before taking turns. Importantly, when a long sentence from the original text was cut into two sentences in the simplified version of the same text, we also presented the two sentences at once to keep the amount of semantic information that is presented similar between the original and simplified versions of the same text.

\section{Materials}

We selected 10 narrative (tales, stories) and 10 scientific texts (documentaries), which were in line with the national school program for that grade level. The scientific texts were extracted from open-access scientific resources for children in primary school (Wapiti, Bibliothèque de Travail Junior, or Images DOC). For literary texts, we used extracts from traditional children's literature used in schools, such as Antoon Krings' collection Drôles de petites bêtes [Funny little creatures], J'aime lire [I like reading], or Réné Goscinny and Jean-Jacques Sempé's novel Le Petit Nicolas [The little Nicolas]. The average length of the overall original texts was 243 words (range: 202-252 words). The texts used in the experiment are part of the Alector corpus (see Appendix A, Gala et al., 2020a).

Text simplifications were carried out manually by a group of researchers from education, cognitive psychology, linguistics, and speech and language therapy. 
The simplifications mainly focused on the lexical and syntactic level and mainly consisted of substituting long and infrequent words by shorter and more frequent synonyms and by changing complex syntactic structures (Gala et al., 2018). Long words were either (a) deleted, such as adverbs like particulièrement [particularly, especially] or rare adjectives like amphibie [amphibious], or (b) replaced by shorter words, such as mousquetaires [musketeers] replaced by soldats [soldiers], au bout de [at the end of] by après [after]. Shorter words tend to be more frequent and are, therefore, more likely to be known by grade 2 . Although the lexical substitutions were easy to perform for literary texts, they were more difficult to make for scientific texts, because specific vocabulary is crucial in the scientific domain. In most cases, we thus decided not to change specialized or technical terms, such as calcaire [calcareous] or atmosphère [atmosphere] unless this was possible (e.g., infiltrer [infiltrate] was replaced by passer [pass through]). Very few simplifications concerned discursive changes, such as when pronouns were changed by their referent to increase the explicitness of coreference chains, for example, "elle rencontra le loup (...) il [he] lui demanda" simplified by "elle rencontra le loup (... ) le loup [the wolf] lui demanda").

For the purpose of lexical simplification, we selected lexical substitutes (synonyms) from the Manulex database (Lété et al., 2004,) and from ReSyf (Billami et al., 2018). The latter is an online lexicon that provides semantically disambiguated synonyms, which are ranked according to their readability. The readability ranking was obtained automatically by using statistical information (word frequencies and morpheme frequencies), lexical information (grapheme-to-phoneme distances, number of spelling neighbors, etc.), and semantics (polysemy) (François et al., 2016). For syntactic simplification, we split sentences that contained subordinated or coordinated clauses. We also transformed long verbal phrases and modified passive to active mode. Simplified texts thus present sentences with only one inflected verb and apart from a few exceptions they follow the standard subject-verb-object structure (e.g., "Jamais elle ne rate son but" transformed into "Elle ne rate jamais son but", where the adverb jamais [never] is moved after the verb). A detail of all the transformations can be found in the guidelines (Gala et al. 2020b). An example of a normal and simplified text from the Alector corpus (Gala et al., 2020a) is provided in Appendix A.

\section{Text readability analysis of the material}

To better understand and describe how our simplified versions differed from the original versions of the same text (e.g., Crossley, Louwerse, McCarthy, \& McNamara, 2007), we made use of some of the standard variables that are typically used in readability formulae (e.g., Flesch, 1948; Kandel \& Moles, 1958). Within the field of readability, it is common to extract a large number of variables from texts (for review see François, 2015). They belong to various feature families, within which all related variables are generally highly redundant (e.g., different kinds of frequency measures). In this research, we started out with a set of 406 variables gathered by François (2011). Note that a large number of the variables are variants of each other and thus measure similar text properties. Following the guidelines of Guyon and Elisseeff (2003), we chose the most important ones through a two-step 
process. That is, we first used domain knowledge to select the most relevant variables and we calculated their values for each of our simplified and original texts. We then used a Wilcoxon-Pratt signed-rank test to evaluate whether a variable significantly differentiated a simplified from an original text. We then checked the distributions of all significant variables and selected the most significant variables that had acceptable normal distributions. This procedure resulted in a selection of 27 variables (see Table 1) that can be organized into three families: 1) lexical, 2) morphological, and 3) syntactic.

\section{Lexical variables}

The first set of 10 variables reflect lexical properties related to word frequency, word length, and orthographic neighborhood. Frequency variables were calculated using Lexique3 (New et al., 2007). We found significant differences for the average frequency of nouns and adjectives but also for the frequency of the 75th and 90th percentiles of the frequency distribution (all words). We found differences for a unigram model, which corresponds to the geometric mean of the log frequencies. Simplified texts also contained less words that were absent from a reference list of the most frequent French words (Gougenheim et al., 1964). In terms of word length, average word length failed to reach significance, but simplified texts had a significantly lower proportion of long words (we used $>8$ letters but we had significant effects also for $>7$ and $>9$ letters). Finally, simplified texts had words with somewhat denser and especially more frequent orthographic neighborhoods (Huntsman \& Lima, 1996).

\section{Morphological variables}

We selected four significant variables that captured the inflectional complexity relative to verbal tenses and moods. Simplified texts had a significantly smaller proportion of verbs in the future form, verbs in the participle past form, and verbs in the participle present. In contrast, the proportion of verbs in the simple present form was increased in simplified texts.

\section{Syntactic variables}

In terms of syntactic difficulty, we selected a number of variables related to the number of words per sentence, such as the mean, the median, and the 75th or 90th percentiles. We also found that nine part-of-speech (POS) ratios differentiated simplified from original texts. POS ratios are often taken as a proxy for the syntactic complexity of sentences (Bormuth, 1966).

\section{Comprehension questions}

After each text, participants received five multiple-choice comprehension questions. Internal reliability of this measure was high with a Cronbach's alpha of 0.954 . The percentage of correct answers was $84.2 \%$ for participants (quartiles: $75.3 \%$ and $90.0 \% ; \mathrm{N}=149$ participants) and $85.5 \%$ for questions (quartiles: $75.3 \%$ and $91.3 \% ; \mathrm{N}=100$ questions). Two types of questions were used: retrieval-type 
Table 1. Selected readability variables for simplified and original versions of the texts. Standard deviations in parenthesis

\begin{tabular}{|c|c|c|c|}
\hline & $\begin{array}{l}\text { Simplified } \\
\text { texts }\end{array}$ & Original texts & Sig. \\
\hline \multicolumn{4}{|l|}{ Lexical variables } \\
\hline $\begin{array}{l}\text { 75th percentile of the frequency distribution of the } \\
\text { lemmas }\end{array}$ & $183.9(176.2)$ & $119.4(96.8)$ & $<.001^{\star \star \star}$ \\
\hline $\begin{array}{l}\text { 90th percentile of the frequency distribution of the } \\
\text { lemmas }\end{array}$ & $18.3(11.7)$ & $11.8(8.0)$ & $.002^{\star \star}$ \\
\hline Average frequency of adjectives (lemma) & $1592.2(1013.4)$ & $1122.2(808.5)$ & $.001^{\star *}$ \\
\hline Average frequency of nouns (lemma) & $202.1(114.1)$ & $177.1(73.6)$ & $.015^{*}$ \\
\hline $\begin{array}{l}\text { Median of the frequency distribution of the } \\
\text { adjectives (lemmas) }\end{array}$ & $479.3(474.1)$ & $367.0(445.8)$ & $.023^{*}$ \\
\hline $\begin{array}{l}\text { Unigram model based on part-of-speech } \\
\text { disambiguated inflected forms }\end{array}$ & $-772.2(29.0)$ & $-792.5(32.9)$ & $.001^{\star \star}$ \\
\hline Proportion of words longer than eight letters & $.058(.031)$ & $.073(.030)$ & $.003^{\star *}$ \\
\hline $\begin{array}{l}\text { Proportion of words absent from Gougenheim's list } \\
\text { of } 1,063 \text { words }\end{array}$ & $.199(.065)$ & $.223(.059)$ & $<.001^{\star \star \star}$ \\
\hline $\begin{array}{l}\text { Proportion of words absent from Gougenheim's list } \\
\text { of 2,000 words }\end{array}$ & $.150(.051)$ & $.172(.045)$ & $<.001^{\star \star \star}$ \\
\hline $\begin{array}{l}\text { Average number of higher-frequency orthographic } \\
\text { neighbors }\end{array}$ & $1.047(.282)$ & $0.895(.273)$ & $.006^{\star *}$ \\
\hline \multicolumn{4}{|l|}{ Morphological variables } \\
\hline Proportion of verbs in the future form & $.015(.030)$ & $.018(.023)$ & $0.03^{*}$ \\
\hline Proportion of verbs in the participle past form & $.093(.054)$ & $.124(.065)$ & $.007^{\star \star}$ \\
\hline Proportion of verbs in the simple present form & $.425(.246)$ & $.387(.242)$ & $.006^{\star \star}$ \\
\hline Proportion of verbs in the participle present form & $.012(.015)$ & $.028(.020)$ & $.002^{\star *}$ \\
\hline \multicolumn{4}{|l|}{ Syntactic variables } \\
\hline $\begin{array}{l}\text { 75th percentile of the distribution of the number of } \\
\text { words per sentence }\end{array}$ & $16.8(3.8)$ & $20.9(6.6)$ & $<.001^{\star \star \star}$ \\
\hline $\begin{array}{l}\text { 90th percentile of the distribution of the number of } \\
\text { words per sentence }\end{array}$ & $20.4(4.1)$ & $27.2(11.3)$ & $<.001^{\star \star \star}$ \\
\hline Median number of words per sentence & $11.9(2.4)$ & $15.2(5.4)$ & $.001^{\star \star}$ \\
\hline Average number of words per sentence & $13.2(2.5)$ & $16.9(6.3)$ & $<.0001^{\star \star \star}$ \\
\hline Ratio of prepositions to all articles & $.762(.220)$ & $.809(.204)$ & $.048^{\star}$ \\
\hline Proportion of pronouns & $.111(.046)$ & $.121(.044)$ & $.003^{\star \star}$ \\
\hline Ratio of articles to all grammatical words & $.360(.085)$ & $.342(.082)$ & $.009^{\star *}$ \\
\hline Ratio of proper nouns to all content words & $.032(.024)$ & $.027(.024)$ & $<.001^{\star \star \star}$ \\
\hline Ratio of proper nouns to adjectives & $.214(.192)$ & $.184(.193)$ & $<.001^{\star \star \star}$ \\
\hline Proportion of proper nouns & $.018(.014)$ & $.016(.014)$ & $.002^{*}$ \\
\hline
\end{tabular}


Table 1. (Continued)

\begin{tabular}{lccc}
\hline & Simplified & & \\
texts & Original texts & Sig. \\
\hline Ratio of proper nouns to pronouns & $.173(.153)$ & $.129(.124)$ & $<.001^{\star \star \star}$ \\
\hline Ratio of pronouns to content words & $.195(.083)$ & $.214(.082)$ & $<.001^{\star \star *}$ \\
\hline Ratio of pronouns to common nouns & $.555(.343)$ & $.604(.344)$ & $.004^{\star \star}$ \\
\hline
\end{tabular}

Table 2. Descriptive statistics for the 11 cognitive and language tasks along with measures of skewness, kurtosis, and reliability (Cronbach's alpha). Reliability for reading aloud and RAN is based on a split-half method

\begin{tabular}{|c|c|c|c|c|c|c|}
\hline Variables & Min-Max & Average & SD & Skewness & Kurtosis & Reliability \\
\hline Phoneme awareness (\%) & $0-100$ & 58.79 & 27.50 & -.64 & -.65 & .83 \\
\hline Reading aloud (words per sec) & $.27-1.57$ & .79 & .22 & .57 & .69 & .85 \\
\hline Vocabulary (/60) & $28-56$ & 45.28 & 5.26 & -.43 & .19 & .59 \\
\hline Oral comprehension (/8) & $1-8$ & 6.37 & 1.53 & -1.19 & 1.52 & .54 \\
\hline Working memory $(/ 16)$ & $3-13$ & 7.10 & 1.70 & .59 & 0.52 & .65 \\
\hline Nonverbal intelligence (/36) & $6-32$ & 22.15 & 4.80 & -.27 & -.03 & .78 \\
\hline Morphological sensitivity (/12) & $0-12$ & 5.82 & 2.89 & .05 & -.83 & .83 \\
\hline Word recognition (/40) & $5-33$ & 18.11 & 5.24 & .03 & .16 & .75 \\
\hline Spelling: morphology (/45) & $12-45$ & 35.93 & 7.18 & -1.27 & 1.64 & .86 \\
\hline Spelling: grammar (/31) & $1-26$ & 11.75 & 5.30 & .20 & -.61 & .70 \\
\hline RAN (sec) & $10.2-27.4$ & 15.54 & 3.17 & 0.95 & 1.01 & .47 \\
\hline
\end{tabular}

questions and questions that required participants to make inferences (e.g., Cain et al., 2001). Because the texts were very short, there were more retrieval-type than inference-type questions ( $82 \%$ vs. $18 \%$ ). The questions were identical for simplified and original texts.

\section{Cognitive and language tests}

Ten tests were used to assess the individual cognitive and language profile of each participant (see Table 2). They were administered in the same order for each participant.

\section{Phonological awareness}

A computerized test (Evalec) was used to assess phonological awareness skills (Sprenger-Charolles et al., 2005; 2010). We used the phoneme deletion subtest, in which children were presented with Consonant-Consonant-Vowel (CCV) 
spoken pseudowords and had to delete the first phoneme. They responded by pronouncing the remaining CV sequence. The test had 12 items.

\section{Reading aloud}

We used the French version of the Test of Word Reading Efficiency (TOWRE) adapted to French by Gentaz and colleagues (2015). This test contained a list of familiar words which had to be read aloud in 1 min (60 words, five per line) and a list of pseudowords ( 60 words, five per line). The words were among the 1000 most frequent words in grade 1 textbooks (Lété et al., 2004). The pseudowords were matched to the words in length, syllabic structure, and spelling. Twenty of the pseudowords had a grapheme whose pronunciation depended on the context $(\mathrm{s}=\mid \mathrm{s} /$ or $|z| \ldots)$. For the purpose of our analyses, we collapsed words and pseudowords into a single reading speed measure. To assess the reliability of the test, we calculated the correlation between words and pseudowords, which was .847 .

\section{Vocabulary}

Vocabulary was assessed using the Test de Vocabulaire Actif/Passif (TVAP), a standardized vocabulary test for children aged between 5 and 8 years (Deltour \& Hupkens, 1980). In this test, the student had to select one image out of six that corresponded to the word provided by the examiner. The test consisted of 30 words, 2 points per correct answer and 1 point for an approximate answer.

\section{Oral comprehension}

To assess the comprehension of syntactic and semantic information, we used a standardized French test called Epreuve de Compréhension Syntaxico-Sémantique Etalonnée (ECOSSE) developed by Lecocq (1996). In this test, a spoken sentence is given to the student, who must select the corresponding image among four possibilities, two of which contain lexical or grammatical traps. The test is designed to use a variety of syntactic structures, the complexity of which increases during the test. Because quite a few items were at ceiling, which produced a highly non-normal distribution, we eliminated all items with an accuracy rate above $95 \%$. This left us with eight items (M11, M24, M42, N21, N44, P22, P33, and RNouv33) for which we obtained excellent psychometric properties (see Table 2). The test was computerized, such that each student was tested in the same conditions.

\section{Working memory}

We used the standard forward digit span from the Wechsler intelligence scale for children (Wechsler, 2004). The experimenter pronounced a series of digits and children were asked to orally recall the series in the same order. The test started with two 2-digit series, followed by two 3-digit series, and so on up to two 9-digit series. Therefore, the maximum number of correct responses was 16 . When children made two consecutive errors, the sequence was stopped. 
Nonverbal intelligence

We used the Progressive Raven Matrices test (Raven 1998), which consists of 36 items divided into 3 sets of 12 items (set A, set AB, and set B). Each item represents a geometric figure with a missing part and the participant had to choose one out of six pieces to complete the figure.

\section{Morphology}

We used a sentence completion task to measure morphological sensitivity (Casalis et al., 2004). In this test, children had to complete a sentence using a derived form of a word whose root was provided in the first part of the sentence (e.g., "someone who hunts is a..."..."hunter"). We used the suffixed form which contains 12 items.

\section{Visual word recognition}

We used a standardized visual word recognition test, the Test d'identification de mots écrits (Timé 3) developed by Écalle (2006). In this test, a total of 40 visually presented words must be identified in 2 tasks, a picture-word matching and a word association task. The score obtained is the total number of correct responses across both tasks.

\section{Spelling}

We used a standardized French spelling test, the Langage oral - Langage écrit - Mémoire, Attention test (L2MA, $2^{\text {nd }}$ edition; Chevrie-Muller et al., 2010). In this test, seven sentences were dictated to the student and accuracy was coded on two dimensions, morphology (45 points) and grammar (31 points). Spelling errors that did not fall into these dimensions were not taken into account.

\section{Rapid automatized naming}

The children were presented with four lines of nine digits on a computer screen (same order for all participants). They had to name them as quickly as possible. We measured the total time to name the 36 digits, which was converted into a speed measure (digits per second). Split-half reliability was .472 .

\section{Results}

As concerns the digital text reading, we calculated the RT by dividing the on-screen display duration of each sentence by the number of words of each sentence (resulting in a time per word) and by the number of characters of each sentence (resulting in a time per character, used to remove aberrant values). As shown in Appendix B, the two RT distributions exhibited a bimodal distribution, reflecting the fact some responses were abnormally short probably due to rapid skipping of a sentence (lack of interest and inability to read the text) or involuntary anticipatory responses. We therefore applied a rigorous data trimming procedure to exclude such artifactual data points. We also removed participants and texts that did not have a sufficient number of valid data points. The procedure is fully 
described in Appendix B. It is important to note that such a rigorous trimming procedure was necessary because the reading data came from self-paced reading in fairly young children in real classroom conditions. Thus, children could skip several lines or an entire text if they did not feel like reading and there was no external monitoring that would have prevented them from doing so. As shown in Appendix B, the final analysis included data from 2,600 texts (out of 3,300 initially) and 149 participants (out of 165 initially).

RTs were log-transformed to normalize RT distributions (see Appendix B). RTs and accuracies were analyzed using mixed effect regression modeling using the lme4 package (Bates et al., 2014) and the lmerTest package (Kuznetsova, Brockhoff, \& Christensen, 2017) in the R environment (RCoreTeam, 2019). Participants and items (i.e., sentences or questions) were used as random variables. The models are specified at the beginning of each of the following sections. Data, R scripts, model specifications, and summaries are available on an open science repository ${ }^{5}$. Additional $\mathrm{R}$ libraries were used for aggregating and transforming data (Wickham et al., 2019), plotting model results (sjPlot; Lüdecke, 2021), estimating model means (emmeans; Lenth, 2021), and computing principal component analyses (PCAs) (psych; Revelle, 2021).

\section{Effects of simplification on reading speed and comprehension}

The effects of simplification on RTs (milliseconds per word) are presented in Figure 1 for both literary and scientific texts. These effects were analyzed using a linear mixed effect model with Simplification (original vs. simplified) and Type of text (literary vs. scientific) as fixed factors and child and sentence as random factors [formula: $\operatorname{lmer}(\mathrm{RT} \sim$ Simplification $\mathrm{x}$ TypeOfText $+(1 \mid$ Sentence $)+$ $(1+$ Simplification $\mathrm{x}$ TypeOfText $\mid$ Child $)]$. The analysis revealed a significant effect of Simplification $(b=-0.03, S D=0.009, t=-3.5)$ and Type of text $(b=0.02$, $\mathrm{SD}=0.008, \mathrm{t}=2.73)$ on RTs, with no significant interaction between these two factors $(t=1.16)$. These effects reflect the fact that simplified texts were read faster than original texts (estimated marginal effect size of $44 \mathrm{~ms}$ per word) and that scientific texts were read slower than literary texts (estimated marginal effect size of $57 \mathrm{~ms}$ ). Despite a small tendency for smaller simplification gains in scientific than literary texts (cf. Figure 1), the critical interaction failed to reach significance.

The results for comprehension (MCQ) are presented in Figure 2A. We had both retrieval-type and inference-type questions, and the results of simplification on the type of question are presented in Figure 2B. The results were analyzed using two logistic mixed effect model with Simplification (original vs. simplified) and Type of text (literary vs. scientific) for the first model, and Simplification and Type of question (retrieval vs. inference) for the second model as fixed factors [model 1 formula: glmer(Accuracy $\sim$ Simplification $\times$ TypeOfText $+(1)$ Question $)+(1+$ Simplification + TypeOfText|Child $)$; model 2 formula: glmer(Accuracy $\sim$ Simplification $\times$ TypeOfQuestion + (1|Question) + $(1+$ Simplification + TypeOfQuestion|Child)]. For the first model, we obtained a significant effect of Simplification $(b=0.55, S D=0.09, z=6.23)$, which reflected the fact that comprehension was better for simplified than for original texts (estimated marginal effect size of 3.97\%). Type of text did not reach significance, 


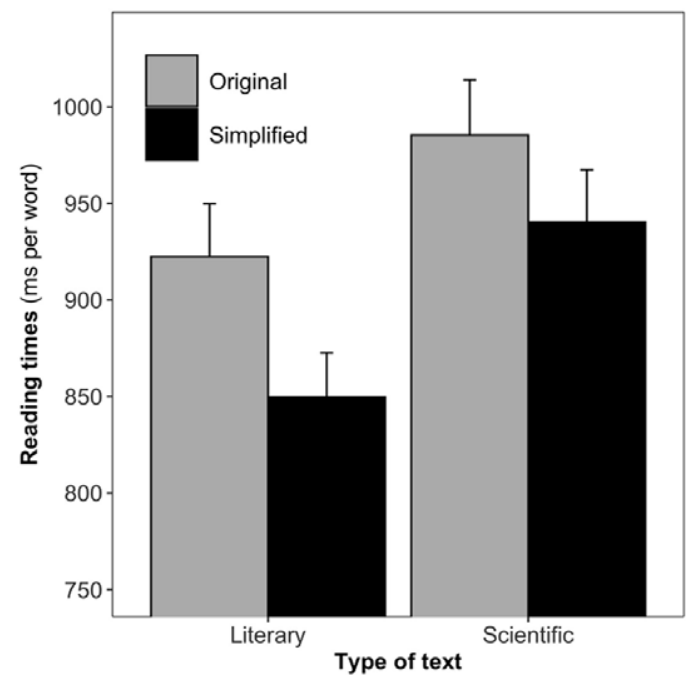

Figure 1. Reading times (in milliseconds, $m s$ ) per word for original and simplified versions of literary and scientific texts. Error bars are standard errors.

(A)

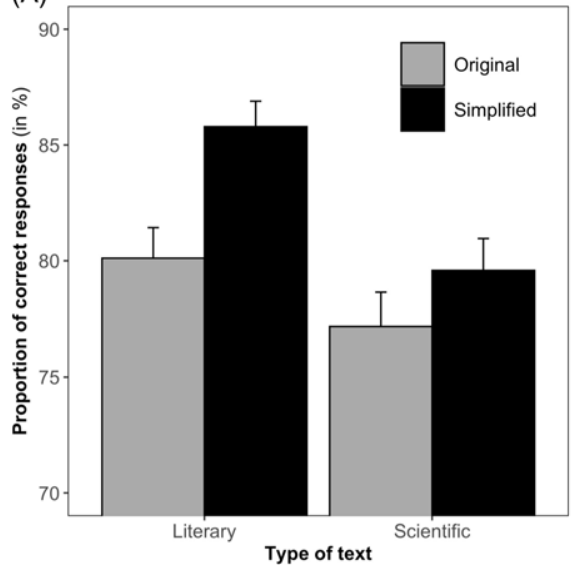

(B)

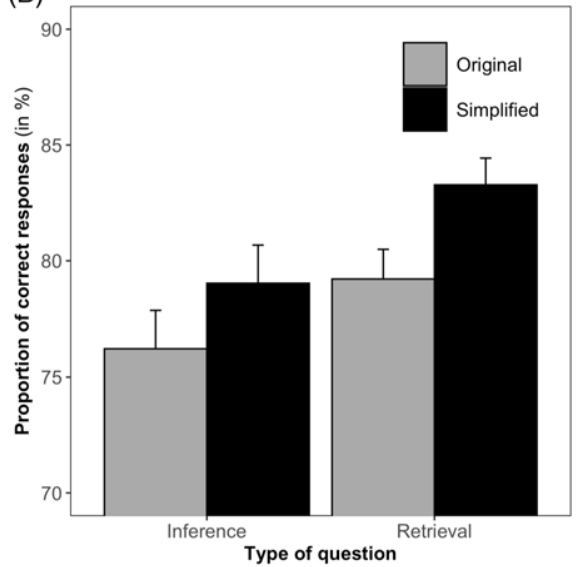

Figure 2. Results from the comprehension test. A. Proportion of correct responses (in percent) for simplified and original literacy and scientific texts. B. Proportion of correct responses for the simplified and original texts as a function of the type of question (retrieval-type vs. inference-type). Error bars are standard errors.

but the interaction between Type of text and Simplification was significant $(\mathrm{b}=-0.36, \mathrm{SD}=0.11, \mathrm{z}=-3.28)$, which reflects the fact that simplification yielded stronger effects for literary than scientific texts. Yet, the contrast analysis showed that simplification was still significant for both type of texts $(z=-6.23$ and 
Table 3. Loadings of cognitive and language variables on principal components ( $\mathrm{C} 1$ to $\mathrm{C} 4$ ) computed from a varimax-rotated principal component analysis. Figures in bold are greater than 0.5

\begin{tabular}{|c|c|c|c|c|}
\hline & \multicolumn{4}{|c|}{ Components } \\
\hline & $\mathrm{C} 1$ & $\mathrm{C} 2$ & $\mathrm{C} 3$ & C4 \\
\hline & Reading & Vocabulary & Spelling & Nonverbal \\
\hline \multicolumn{5}{|l|}{ Variables } \\
\hline Phoneme awareness & 0.47 & 0.25 & -0.39 & 0.41 \\
\hline Reading aloud & 0.79 & 0.05 & 0.23 & 0.18 \\
\hline Vocabulary & 0.18 & 0.71 & 0.06 & 0.12 \\
\hline Oral comprehension & 0.17 & 0.82 & -0.02 & 0.09 \\
\hline Working memory & -0.02 & 0.09 & 0.11 & 0.82 \\
\hline Nonverbal intelligence & 0.23 & 0.18 & 0.01 & 0.73 \\
\hline Morphological sensitivity & -0.01 & 0.67 & 0.30 & 0.16 \\
\hline Word recognition & 0.68 & 0.23 & 0.28 & 0.14 \\
\hline Spelling: morphology & 0.59 & 0.13 & 0.61 & 0.13 \\
\hline Spelling: grammar & 0.23 & 0.2 & 0.82 & 0.07 \\
\hline RAN & -0.78 & -0.1 & 0.01 & 0.02 \\
\hline
\end{tabular}

RAN, Rapid automatized naming.

$\mathrm{z}=-2.33$ for literary and scientific text, respectively). Concerning the second model, the effect of simplification was significant $(b=0.36, S D=0.13, z=2.86)$ and produced a marginal effect of $4.11 \%$ in favor of simplified texts. The analyses did not reveal an effect of Type of question neither as a simple effect nor as an interaction. This suggests that simplification worked equally well for both retrieval- and inference-type questions.

\section{Effects of cognitive and language variables on simplification gains}

We were interested in finding out whether simplification was more or less efficient as a function of the cognitive and language profile of the child. For instance, did poor readers or children with poor oral language skills benefit more from simplification than good readers or children with good oral language skills? To address this question, we investigated whether simplification gains in reading speed and comprehension would vary as a function of the performance of the children on our 11 language and cognitive variables. Thus, the idea was to add each cognitive and language variable to the mixed effect model and see whether it had an effect on reading speed and comprehension and whether it interacted with simplification. To reduce the number of multiple comparisons, we first conducted a PCA on the 11 variables. The PCA resulted in a four-component solution and Table 3 shows the loadings of the variables on the four components after a varimax rotation. The first component $(\mathrm{C} 1)$ reflected reading ability, the second component $(\mathrm{C} 2)$ oral 
language and vocabulary skills, the third component (C3) spelling ability, and the fourth component (C4) nonverbal intelligence and working memory.

We then introduced the factor scores on these four components and their interaction with simplification in the linear mixed effect models that predicted reading speed or comprehension scores. A significant effect of a component would mean that the component affects reading speed or comprehension. A significant interaction of the component with simplification would mean that the component modulates the effects of simplification. The $\mathrm{R}$ formula for reading speed was the following: $\operatorname{lmer}(\mathrm{RT} \sim$ Simplification + Simplification $\times \mathrm{C} 1+$ Simplification $\times \mathrm{C} 2+$ Simplification $\mathrm{x}$ C3 + Simplification $\mathrm{x} \mathrm{C4}+(1 \mid$ Sentence $)+(1 \mid$ Child $)$. The results are presented in Table 4 (upper part).

As can be seen in Table 4, apart from C2 (oral language and vocabulary), all other components were associated with reading speed. Importantly, there was a significant interaction between the effects of simplification and a participant's reading competence $(\mathrm{C} 1)$. This interaction is plotted in Figure 3 using the R libraries Emmeans and sjPlots (Lenth, 2021; Lüdecke, 2021). As can be seen, simplification gains (difference between simplified and original texts) were larger for poor readers (Normalized Units $<0$ ) than for good readers (Normalized Units $>0$ ).

The same analysis was performed for comprehension scores. However, to take into account the fact that in the main analysis presented above, the effects of simplification on comprehension were different for scientific versus literacy texts (i.e., we obtained a significant Simplification $\mathrm{x}$ TypeOfText interaction), we conducted two separate analyses, one for literary and one for scientific texts. The $\mathrm{R}$ formula for the analyses of the comprehension scores was glmer(Accuracy Simplification + Simplification $\times \mathrm{C} 1+$ Simplification $\times \mathrm{C} 2+$ Simplification $\times$ $\mathrm{C} 3+$ Simplification $\times \mathrm{C} 4+(1 \mid$ Question $)+(1 \mid$ Child $))$. The results are presented in Table 4. We found that all components were associated with comprehension. For scientific texts only, C4 (nonverbal intelligence and working memory) showed a significant interaction with comprehension reflecting the fact that simplification gains were stronger for children with poor nonverbal intelligence and weak working memory. $\mathrm{C} 1$ showed a marginally significant interaction $(p=.051)$. Both interactions are plotted in Figure 4.

As can be seen in Figure 4, simplification gains for comprehension (i.e., the difference between simplified and original texts) were greater for participants with weaker reading performance (Normalized Units $<0$, Panel A) and weaker nonverbal intelligence (Normalized Units $<0$, Panel B). This was true for scientific texts only. The logarithmic curvature of the slopes suggests that comprehension benefits were amplified for children with very poor reading or nonverbal intelligence.

\section{Discussion}

The general aim of our study was to investigate whether text simplification could improve reading fluency and comprehension in primary school. Previous studies have mainly looked at the effects of text simplification in special-needs populations, such as illiterates or readers with dyslexia (Gala \& Ziegler, 2016; Margarido et al., 2008; Rello et al., 2013). In the present study, we investigated whether text simplification could be beneficial for normally developing beginning readers in a regular 
Table 4. Effects of the four principal components reflecting the children's cognitive and language profiles on reading speed and comprehension (simple effect) and their interaction with the effects of simplification (interaction). Coefficients result from mixed effect models described in the text

\begin{tabular}{|c|c|c|c|c|}
\hline & \multicolumn{4}{|c|}{ Components } \\
\hline & $\begin{array}{l}\text { Reading } \\
\text { (C1) }\end{array}$ & $\begin{array}{c}\text { Vocabulary } \\
\text { (C2) }\end{array}$ & $\begin{array}{l}\text { Spelling } \\
\text { (C3) }\end{array}$ & $\begin{array}{c}\text { Nonverbal } \\
\text { (C4) }\end{array}$ \\
\hline \multicolumn{5}{|l|}{ RTs } \\
\hline \multicolumn{5}{|c|}{ Simple effect } \\
\hline Beta & -0.080 & -0.008 & -0.024 & -0.026 \\
\hline $\mathrm{t}$ & $-8.92^{\star \star \star}$ & -0.92 & $-2.70^{\star \star}$ & $-2.96 \star \star$ \\
\hline \multicolumn{5}{|c|}{ Interaction } \\
\hline Beta & 0.004 & -0.003 & 0.002 & -0.000 \\
\hline $\mathrm{t}$ & $2.53^{\star}$ & -1.84 & 1.30 & -0.04 \\
\hline \multicolumn{5}{|c|}{ Comprehension: literary texts } \\
\hline \multicolumn{5}{|c|}{ Simple effect } \\
\hline Beta & 0.440 & 0.415 & 0.232 & 0.204 \\
\hline z & $5.33^{\star \star \star}$ & $5.08^{\star \star \star}$ & $2.86^{\star \star}$ & $2.43^{\star}$ \\
\hline \multicolumn{5}{|c|}{ Interaction } \\
\hline beta & -0.029 & 0.049 & -0.009 & -0.015 \\
\hline z & -0.37 & 0.65 & -0.12 & -0.19 \\
\hline \multicolumn{5}{|c|}{ Comprehension: scientific texts } \\
\hline \multicolumn{5}{|c|}{ Simple effect } \\
\hline Beta & 0.529 & 0.246 & 0.223 & 0.364 \\
\hline z & $6.59^{\star \star \star}$ & $3.12^{\star \star}$ & $2.86^{\star \star}$ & $4.51^{\star \star \star}$ \\
\hline \multicolumn{5}{|c|}{ Interaction } \\
\hline beta & -0.137 & 0.098 & 0.015 & -0.167 \\
\hline z & -1.95 & 1.44 & 0.22 & $-2.31^{\star}$ \\
\hline
\end{tabular}

Note. ${ }^{\star} p<.05 ;{ }^{\star \star} p<.01 ;{ }^{\star \star \star} p<.001$.

classroom context. Indeed, recent national evaluations suggest that $40 \%$ of 15-year-old pupils are not able to identify the theme or the main subject of a text, do not comprehend implicit information, and are unable to link two separate explicit information in a text (CEDRE, 2015). In addition, it is well known that children from socially disadvantaged backgrounds tend to show greater reading comprehension problems (Fluss et al., 2009). Thus, finding ways to improve reading fluency and comprehension for children who struggle with learning to read is of outmost importance.

Our results showed that text simplification clearly improved RTs. Note that RTs were calculated per word, which controls for the fact that simplified texts tended to contain fewer words. With respect to comprehension, we found similar text 


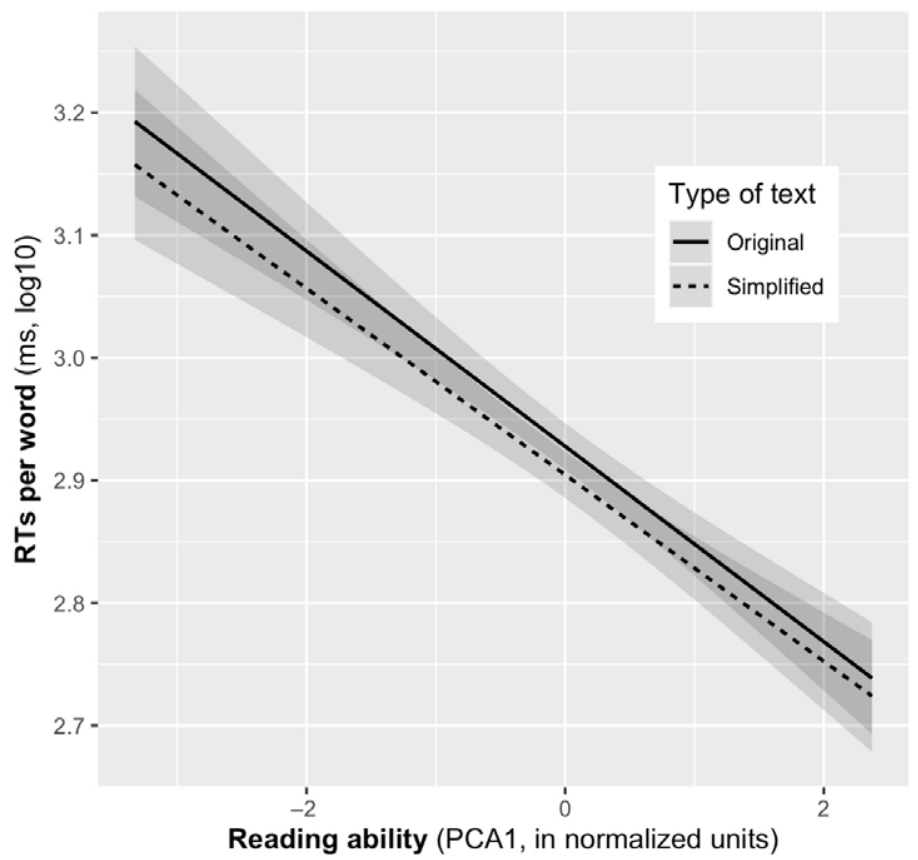

Figure 3. Modulation of reading speed (milliseconds per word, log10, y-axis) as a function of reading ability (PCA1, normalized units, $x$-axis). Solid and dashed lines are the estimated reading times for original and simplified texts at different levels of reading ability. Semitransparent areas are confidence intervals.

(A)

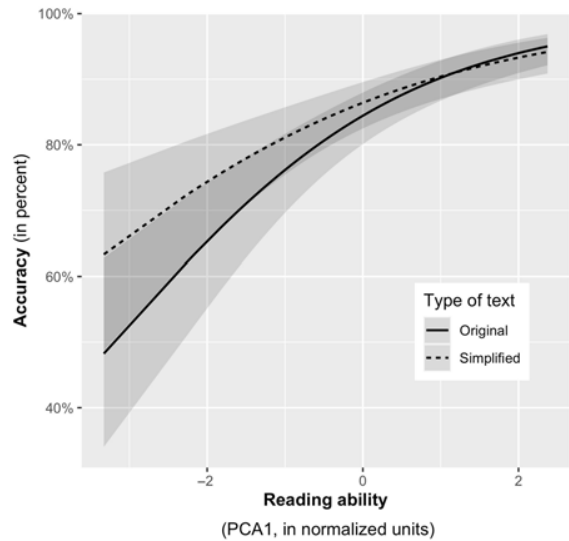

(B)

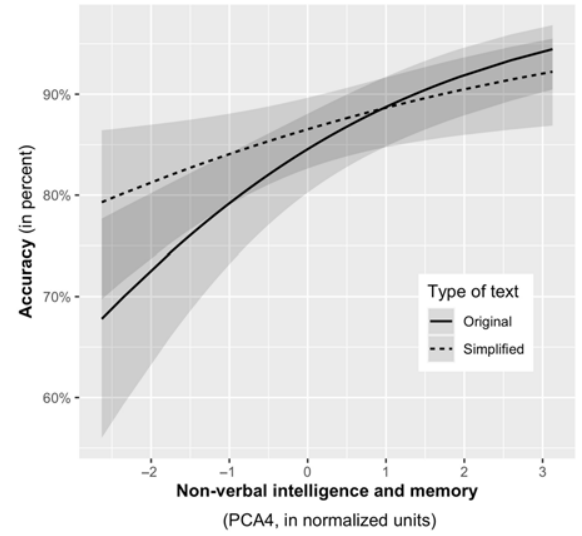

Figure 4. Text comprehension accuracy (percent correct, Y-axis) as a function of reading ability (A) and nonverbal intelligence (B). Solid and dashed curves are the estimated accuracies at different levels of the component variable (in standardized units, X-axis). Semi-transparent areas are confidence intervals. 
simplification benefits, that is, better comprehension for simplified than original texts. Importantly, children answered the exact same comprehension questions for simplified and normal texts, which makes this a well-controlled comparison. It is interesting to note that our text simplification did not result in a speedcomprehension trade-off that is typically found in studies that focus on improving reading speed (for a detailed discussion, see Rayner et al., 2016). Instead, we clearly show that text simplification improves both comprehension and reading speed in beginning readers.

\section{Do some readers benefit more than others from simplification?}

Concerning the question as to whether some readers would benefit more than others from simplification, we obtained two interesting interactions between the cognitive and language profiles of our children and the effects of simplification on fluency and comprehension (see Table 4). As illustrated in Figures 3 and 4 for fluency and comprehension, respectively, children with poor reading skills (first PCA component) showed the greatest simplification benefits in reading fluency and to a smaller extent in comprehension (marginally significant effect). This result confirms our prediction that text simplification should be particularly beneficial for poor readers. This was expected because we changed infrequent and long words with more frequent and shorter words, which should have been easier to read for children with poor reading skills. As noted previously, beginning readers rely to a great extent on decoding (Ziegler, Perry \& Zorzi, 2020), but the impact of decoding on reading comprehension seems to decrease as children become more proficient readers (e.g., Verhoeven \& Van Leeuwe, 2008). Thus, it is an open question to what extent simplification is useful for more proficient readers.

In contrast to our predictions, however, we did not find significant interaction between the effect of simplification and vocabulary/oral language skills (second PCA component), although this component was clearly related to overall reading speed and comprehension (see the effects in Table 4). While it is important not to overinterpret null effects, the absence of an interaction between simplification and the oral language component seems to suggest that simplification was beneficial for beginning readers regardless of whether they had good or poor vocabulary or oral comprehension. We should note, however, that the vocabulary and oral language tests were quite short and might not have been sufficiently sensitive to fully assess the oral language skills of our sample.

We also found a significant interaction between the effects of simplification and nonverbal intelligence/memory (fourth component) on comprehension. The effect of nonverbal intelligence/memory on comprehension was positive: children with higher nonverbal intelligence and better memory were better comprehenders (Colé et al., 2014). Yet, the interaction with the effects of simplification was negative, which suggests that children with weaker nonverbal intelligence and/or weaker memory skills benefit to a greater extent from simplification.

However, it should be acknowledged that potential ceiling effects in comprehension could undermine the conclusion that simplification does not benefit good readers as much as poor readers. More skilled readers may already be too fluent 
and comprehend the passages too well for simplification to improve their scores. When performance is over $90 \%$ on the original texts for "good to very good" readers (see Figure $4, \mathrm{z}_{\text {reading ability }}>1$ ), there might be little room left for simplification to improve things.

Taken together, with this caveat in mind, the overall results seem to suggest that poor readers and children with weaker cognitive abilities seem to benefit to a greater extent from text simplification. This supports the hypothesis that the major effect of simplification is that it renders word recognition and decoding more efficient, which has direct effects on reading fluency and text comprehension as predicted by the simple model of reading (Gough \& Tunmer, 1986; Hoover \& Gough, 1990).

\section{Does simplification work better on literary than on scientific texts?}

With respect to comprehension, our results showed that simplification yielded stronger effects for literary than for scientific texts. A similar trend was observed for reading speed, although the interaction failed to reach significance. This might be somewhat surprising because scientific texts are typically longer, contain more infrequent words, and are conceptually more complex (Hiebert \& Cervetti, 2012). Thus, they should have benefitted to a greater extent from simplification than literary texts. However, it was much more difficult to simplify scientific texts because they tended to use a very specific low-frequency vocabulary, for which it was not always possible to find more frequent synonyms. For example, in our sentence, Algae produce more than half of the oxygen in our air, neither algae nor oxygen can be replaced by more frequent synonyms. In addition, we selected informational texts that were used in the school curriculum. They were written in a rather simplified journalistic style using somewhat shorter sentences (14.2 vs. 16.1 words per sentence, for scientific vs. narrative texts, respectively).

The overall difficulty with scientific texts highlights the importance of specifically using such reading material in classroom interventions. Indeed, Kim et al. (2021) showed that having young children read science documentaries with content literacy instruction can help them develop concept-related vocabulary while fostering domain knowledge in science and increasing general reading interest.

\section{Limitations and future directions}

There are a few limitations of our study. First, given that we simplified at three linguistic levels (lexical, morphosyntactic, and discursive) and although lexical simplifications were by far more frequent than the two other types, it is currently not possible to precisely dissociate the effects at each level. Future work is needed to pull apart the effects at each level. Second, all simplifications were made manually. Although we used rigorous rules and computational tools to help us make the simplifications, such as an online lexicon that provides semantically disambiguated synonyms ranked for their readability (ReSyf, Billami et al., 2018), we fully acknowledge a subjective part of making some of the simplifications. We are currently working on a fully automatic simplification system for French ${ }^{6}$, which should solve this limitation in the future (see Saggion, 2017). Third, we did not manage to use the same number of inference- and retrieval-type questions, which was partially due to 
the fact that the texts were short making it difficult to come up with inference-type questions.

There are two general limitations of text simplification that are worth discussing. This first is that changing words in a text might cause a loss of a text's authenticity. Indeed, authors do not choose words at random but they use words that best fit their communicative purpose or serve a poetic function. Researchers in text simplification are well aware of this problem, which is why the focus is on "retaining the original information and meaning" (Siddharthan, 2014, p. 259) rather than preserving the original style. As a matter of fact, synonyms rarely carry the exact same meaning and some semantic nuances might be lost when replacing complex words by simpler words. The second limitation is that simplified texts are not always available in every situation in the reading journey of a poor comprehender. Thus, even if text simplification is beneficial for poor readers, it remains of outmost importance to develop general intervention programs that bring poor comprehenders to the level of typically developing readers (see Bianco et al., 2010, 2012).

In terms of future directions, it would be important to test whether benefits of simplification can be obtained beyond grade 2 . We are currently undertaking a longitudinal study to address this issue. Furthermore, it would be important to find out whether the effects of simplification have a long-lasting general effect on improving reading skills. That is, if we were to give reading-level appropriate simplified material to poor readers for some period of time, would we be able to show that they improved general reading comprehension skills compared to a group of students who did not receive reading-level adapted simplified material? Finally, given that our iBook application measures reading speed and comprehension for each text online, one can easily imagine that the system automatically chooses the "right" level of difficulty. If reading is slow and comprehension is poor, the child would receive easier or simplified texts, if reading is fast and comprehension is good, readers would receive more difficult texts that are not simplified. Thus, such a system would be able to track students' performance and propose adapted texts as a function of the student's reading and comprehension level. With the rise of artificial intelligence and deep-learning tools in education, such a system could use the online player data to optimize the selection and simplification of texts with respect to the needs of the students.

Acknowledgments. Our friend and colleague Jacques Ginestié passed away in September 2020; this article is dedicated to his memory. This work has been supported by the pilot center on teacher training and research for education (AMPIRIC), funded by the Future Investment Programme (PIA3), and the center of excellence on Language, Communication and Brain (ILCB), funded by the French National Agency for Research (ANR, ANR-16-CONV-0002) and the Excellence Initiative of Aix-Marseille University $A^{*}$ MIDEX (ANR-11-IDEX-0001-02). The research was directly funded through grants from the ANR, ALECTOR (ANR-16-CE28-0005) and MORPHEME (ANR-15-FRAL-0003-01) and the ERC (Advanced grant 742141). The authors thank all the participants, the teachers who accepted to use the iBooks in their classrooms, and the school authorities who supported this study, especially Olivier Millangue, Nathalie Greppo-Chaignon, and Géraldine Gaudino. We also thank the Communauté d'Agglomération Sud Sainte Baume for providing access to the iPads used in the schools and technical support. We finally thank Marco Bressan for his support regarding the statistical analyses, the research assistants for their help in the data collection of the cognitive tasks, and the children of the co-authors who helped improve the iBook interface. 


\section{References}

Adlof, S. M., Catts, H. W., \& Little, T. D. (2006). Should the simple view of reading include a fluency component? Reading and Writing, 19(9), 933-958. doi: 10.1007/s11145-006-9024-Z

Andreu, S., Cioldi, I., Conceicao, P., Etève, Y., Fabre, M., Tidiane Ndiaye, C. A., Portelli, T., Rocher, T., Vourc'h, R. \& Wuillamier, P. (2019). "Évaluations repères 2018 de début de CE1 : premiers résultats » Note d'information $N^{\circ} 19.14$, Direction de l'Évaluation, de la Prospective et de la Performance (DEPP).

Bates, D., Mächler, M., Bolker, B., \& Walker, S. (2014). Fitting linear mixed-effects models using lme4. Journal of Statistical Software, 67(1), 1-48. doi: 10.18637/jss.v067.i01

Best, R. M., Floyd, R. G., \& McNamara, D. S. (2008). Differential competencies contributing to children's comprehension of narrative and expository texts. Reading Psychology, 29, 137-164. doi: 10.1080/ 02702710801963951

Bianco, M., Bressoux, P., Doyen, A. L., Lambert, E., Lima, L., Pellenq, C., \& Zorman, M. (2010). Early training in oral comprehension and phonological skills: Results of a three-year longitudinal study. Scientific Studies of Reading, 14(3), 211-246. doi: 10.1080/10888430903117518

Bianco, M., Pellenq, C., Lambert, E., Bressoux, P., Lima, L., \& Doyen, A. L. (2012). Impact of early code-skill and oral-comprehension training on reading achievement in first grade. Journal of research in reading, 35(4), 427-455. doi: 10.1111/j.1467-9817.2010.01479.x

Billami, M. B., François, T., \& Gala, N. (2018). ReSyf: a French lexicon with ranked synonyms. In Proceedings of the 27th International Conference on Computational Linguistics (COLING 12018), Santa Fe, US, 2570-2581.

Bishop, D. V., \& Snowling, M. J. (2004). Developmental dyslexia and specific language impairment: Same or different?. Psychological Bulletin, 130(6), 858-890. doi: 10.1037/0033-2909.130.6.858

Blum, S., \& Levenston, E. A. (1978). Universals of lexical simplification. Language Learning, 28(2), 399-415. doi: 10.1111/j.1467-1770.1978.tb00143.x

Bormuth, J. R. (1966). Readability: A new approach. Reading Research Quarterly, 1(3), 79-132. doi: $10.2307 / 747021$

Bowyer-Crane, C., Snowling, M. J., Duff, F. J., Fieldsend, E., Carroll, J. M., Miles, J., ... Hulme, C. (2008). Improving early language and literacy skills: Differential effects of an oral language versus a phonology with reading intervention. Journal of Child Psychology and Psychiatry, 49(4), 422-432. doi: 10.1111/j.1469-7610.2007.01849.x

Brouwers, L., Bernhard, D., Ligozat, A. L., \& François, T. (2014). Syntactic sentence simplification for French. Proceedings of the 3rd Workshop on Predicting and Improving Text Readability for Target Reader Populations (PITR), 47-56.

Cain, K., Oakhill, J. V., Barnes, M. A., \& Bryant, P. E. (2001). Comprehension skill, inference-making ability, and their relation to knowledge. Memory \& Cognition, 29(6), 850-859. doi: 10.3758/BF03196414

Casalis, S., Colé, P., \& Sopo, D. (2004). Morphological awareness in developmental dyslexia. Annals of Dyslexia, 54(1), 114-138. doi: 10.1007/s11881-004-0006-Z

CEDRE (2015). Cedre 2015. Nouvelle évaluation en fin de collège : compétences langagières et littératie. Évaluation des acquis des élèves. Note d'information 21, Paris: Direction de l'Evaluation, de la Prospective et de la Performance (DEPP)

Chevrie-Muller, C., Maillart, C., Simon, A. M. \& Fournier, S. (2010). Langage oral, langage écrit, mémoire, 2ème édition : L2MA-2. Paris : Edition du centre de psychologie appliquée (ECPA).

Clerc, I., \& Kavanagh, É. (2006). De la lettre à la page Web: savoir communiquer avec le grand public. Publications du Québec.

Colé, P., Duncan, L. G., \& Blaye, A. (2014). Cognitive flexibility predicts early reading skills. Frontiers in Psychology, 5, 565. doi: 10.3389/fpsyg.2014.00565

Coltheart, M., Rastle, K., Perry, C., Langdon, R., Ziegler, J. (2001). DRC: a dual route cascaded model of visual word recognition and reading aloud. Psychological Review, 108(1), 204-256. doi: 10.1037/0033295x.108.1.204

Crossley, S. A., Louwerse, M. M., McCarthy, P. M., \& McNamara, D. S. (2007). A linguistic analysis of simplified and authentic texts. The Modern Language Journal, 91(1), 15-30. doi: 10.1111/j.1540-4781. 2007.00507.x

Davison, A., \& Kantor, R. (1982). On the failure of readability formulas to define readable texts: A case study from adaptations. Reading Research Quarterly, 17(2), 187-209. doi: 10.2307/747483 
Deltour, J. J., \& Hupkens, D. (1980). Test de Vocabulaire Actif et Passif (T. V.A.P.). Braîne le Château, Belgique : Editions Applications des Techniques Modernes.

Écalle, J. (2006). Timé-3: test d'identification de mots écrits. Mot à mot éditions.

Fajardo, I., Tavares, G., Ávila, V., \& Ferrer, A. (2013). Towards text simplification for poor readers with intellectual disability: When do connectives enhance text cohesion? Research in Developmental Disabilities, 34(4), 1267-1279. doi: 10.1016/j.ridd.2013.01.006

Flesch, R. (1948). A new readability yardstick. Journal of Applied Psychology, 32(3), 221. doi: 10.1037/ h0057532

Fluss, J., Ziegler, J. C., Warszawski, J., Ducot, B., Richard, G., \& Billard, C. (2009). Poor reading in French elementary school: the interplay of cognitive, behavioral, and socioeconomic factors. Journal of Developmental \& Behavioral Pediatrics, 30(3), 206-216. doi: 10.1097/DBP.0b013e3181a7ed6c

François, T. (2011). Les apports du traitement automatique du langage à la lisibilité du français langue étrangère, Ph.D. Thesis, Université Catholique de Louvain.

François, T. (2015). When readability meets computational linguistics: a new paradigm in readability. Revue française de linguistique appliquée, 20(2), 79-97. doi: 10.3917/rfla.202.0079

François, T., Billami, M., Gala, N., \& Bernhard, D. (2016). Bleu, contusion, ecchymose: tri automatique de synonymes en fonction de leur difficulté de lecture et compréhension. In Actes de la conférence Traitement Automatique des Langues (TALN), Paris, France, 15-28.

Gala, N., \& Ziegler, J. (2016). Reducing lexical complexity as a tool to increase text accessibility for children with dyslexia. In Proceedings of the Workshop on Computational Linguistics for Linguistic Complexity (CL4LC), 59-66.

Gala, N., François, T., Javourey-Drevet, L., \& Ziegler, J. C. (2018). La simplification de textes, une aide à l'apprentissage de la lecture. Langue Française, 199(3), 123-131. doi: 10.3917/lf.199.0123

Gala, N., Tack, A., Javourey-Drevet, L., François, T. \& Ziegler, J. C. (2020a). Alector: A Parallel Corpus of Simplified French Texts with Alignments of Misreadings by Poor and Dyslexic Readers. Proceedings of the $12^{\text {th }}$ International Conference on Language Resources and Evaluation for Language Technologies (LREC), May 2020, Marseille, France.

Gala, N., Todirascu, A., Javourey-Drevet, L., Bernhard, L. \& Wilkens, R. (2020b). Recommandations pour des transformations de textes français afin d'améliorer leur lisibilité et leur compréhension. [Guidelines for transforming French texts to improve their readability and comprehension] Report prepared for Agence Nationale de la Recherche (ANR), ALECTOR (ANR-16-CE28-0005), Paris, France.

Gentaz, E., Sprenger-Charolles, L. \& Theurel, A. (2015). Differences in the Predictors of Reading Comprehension in First Graders from Low Socio-Economic Status Families with Either Good or Poor Decoding Skills. PLoS ONE 10(3): e0119581. doi: 10.1371/journal.pone.0119581

Gougenheim, G., Michéa, R., Rivenc, P., \& Sauvageot, A. (1964). L'élaboration du français fondamental (1er degré): Etude sur l'établissement d'un vocabulaire et d'une grammaire de base. [Learning basic French (first level): A study on setting-up a basic vocabulary and grammar]. Paris: Didier.

Gough, P. B., \& Tunmer, W. E. (1986). Decoding, reading, and reading disability. Remedial and Special Education, 7(1), 6-10. doi: 10.1177/074193258600700104

Guyon, I., \& Elisseeff, A. (2003). An introduction to variable and feature selection. Journal of Machine Learning Research, 3, 1157-1182.

Hiebert, E. H., \& Cervetti, G. N. (2012). What differences in narrative and informational texts mean for the learning and instruction of vocabulary. Vocabulary Instruction: Research to Practice, 2, 322-344.

Hoover, W. A., \& Gough, P. B. (1990). The simple view of reading. Reading and Writing, 2(2), 127-160. doi: $10.1007 / \mathrm{BF} 00401799$

Huntsman, L. A., \& Lima, S. D. (1996). Orthographic neighborhood structure and lexical access. Journal of Psycholinguistic Research, 25(3), 417-429. doi: 10.1007/BF01727000

Johnston, T. C., \& Kirby, J. R. (2006). The contribution of naming speed to the simple view of reading. Reading and Writing, 19(4), 339-361. doi: 10.1007/s11145-005-4644-2

Joshi, R. M., \& Aaron, P. G. (2000). The component model of reading: Simple view of reading made a little more complex. Reading Psychology, 21(2), 85-97. doi: 10.1080/02702710050084428

Kandel, L., \& Moles, A. (1958). Application de l'indice de flesch à la langue française. Cahiers Etudes de Radio-Télévision, 19, 253-274.

Kershaw, S., \& Schatschneider, C. (2012). A latent variable approach to the simple view of reading. Reading and Writing, 25(2), 433-464. doi: 10.1007/s11145-010-9278-3 
Kim, J. S., Burkhauser, M. A., Mesite, L. M., Asher, C. A., Relyea, J. E., Fitzgerald, J., \& Elmore, J. (2021). Improving reading comprehension, science domain knowledge, and reading engagement through a firstgrade content literacy intervention. Journal of Educational Psychology, 113(1), 3. doi: 10.1037/ edu0000465

Kirby, J. R., \& Savage, R. S. (2008). Can the simple view deal with the complexities of reading? Literacy, 42(2), 75-82. doi: 10.1111/j.1741-4369.2008.00487.x

Kuznetsova, A., Brockhoff, P. B., \& Christensen, R. H. B. (2017). lmerTest package: Tests in linear mixed effects models. Journal of Statistical Software, 82(13), 1-26. doi: 10.18637/jss.v082.i13

Lecocq, P. (1996). L'ECOSSE: une épreuve de compréhension syntaxico-sémantique [Ecosse: a test of syntactic and semantic understanding]. Lille: Presses Universitaires du Septentrion.

Lenth, R.V. (2021). emmeans: Estimated Marginal Means, aka Least-Squares Means. R package version, 1.6.1. https://CRAN.R-project.org/package=emmeans

Lervåg, A., Hulme, C., \& Melby-Lervåg, M. (2018). Unpicking the developmental relationship between oral language skills and reading comprehension: It's simple, but complex. Child Development, 89(5), 1821-1838. doi: 10.1111/cdev.12861

Lété, B., Sprenger-Charolles, L., \& Colé, P. (2004). MANULEX: A grade-level lexical database from French elementary school readers. Behavior Research Methods, Instruments, \& Computers, 36(1), 156-166. doi: 10.3758/BF03195560

Liebfreund, M.D., \& Conradi, K. (2016). Component skills affecting elementary students' informational text comprehension. Read and Writing, 29, 1141-1160. doi: 10.1007/s11145-016-9629-9

Lüdecke, D. (2021). sjPlot: Data Visualization for Statistics in Social Science. R package version 2.8.9, https://CRAN.R-project.org/package $=$ sjPlot

Margarido, P. R., Pardo, T. A., Antonio, G. M., Fuentes, V. B., Aires, R., Aluísio, S. M., \& Fortes, R. P. (2008). Automatic summarization for text simplification: Evaluating text understanding by poor readers. In Companion Proceedings of the XIV Brazilian Symposium on Multimedia and the Web (310-315). ACM. doi: 10.1145/1809980.1810057

Mullis, I. V. S., Martin, M. O., Foy, P., \& Hooper, M. (2017). PIRLS 2016 International Results in Reading. Retrieved from Boston College, TIMSS \& PIRLS International Study Center at: http://timssandpirls.bc. edu/pirls2016/international-results/

New, B., Brysbaert, M., Veronis, J., \& Pallier, C. (2007). The use of film subtitles to estimate word frequencies. Applied Psycholinguistics, 28(4), 661-677. doi: 10.1017/S014271640707035X

Ouellette, G., \& Beers, A. (2010). A not-so-simple view of reading: How oral vocabulary and visual-word recognition complicate the story. Reading and Writing, 23(2), 189-208. doi: /10.1007/s11145-008-9159-1

Perfetti, C. (2007). Reading ability: Lexical quality to comprehension. Scientific Studies of Reading, 11(4), 357-383. doi: 10.1080/10888430701530730

Perry, C., Zorzi, M., \& Ziegler, J. C. (2019). Understanding Dyslexia Through Personalized Large-Scale Computational Models. Psychological Science, 30(3), 386-395. doi: 10.1177/0956797618823540

Raven, J. (1998). Progressive Matrices Couleurs (PM 38), Progressive Matrices Standard (PM 47), Étalonnage Français.[Ravens Colored Progressive Matrices (PM 38), Standard Progressive Matrices (PM 47), French standardization]. Paris, France: ECPA.

Rayner, K., Schotter, E. R., Masson, M. E. J., Potter, M. C., \& Treiman, R. (2016). So Much to Read, So Little Time: How Do We Read, and Can Speed Reading Help? Psychological Science in the Public Interest, 17(1), 4-34. doi: 10.1177/1529100615623267

RCoreTeam. (2019). R: A language and environment for statistical computing. R Foundation for Statistical Computing, Vienna, Austria. https://www.R-project.org/

Rello, L., Baeza-Yates, R., Dempere-Marco, L. \& Saggion, H. (2013) Frequent words improve readability and short words improve understandability for people with Dyslexia. INTERACT 2013: 14th IFIP TC13 Conference on Human-Computer Interaction. Cape Town, South Africa. doi: 10.1007/ 978-3-642-40498-6_15

Revelle, W. (2021). psych: Procedures for psychological, psychometric, and personality research. Northwestern University, Evanston, Illinois. R package version 2.1.9, https:/CRAN.R-project.org/ package $=$ psych.

Saggion, H. (2017). Automatic Text Simplification. Synthesis Lectures on Human Language Technologies, Califormia, Morgan \& Claypool Publishers. doi: 10.2200/s00700ed1v01y201602hlt032 
Schneps, M. H., Thomson, J. M., Chen, C., Sonnert, G., \& Pomplun, M. (2013). E-Readers Are More Effective than Paper for Some with Dyslexia. PLoS ONE, 8(9), e75634. doi: 10.1371/journal.pone.0075634

Selzer, J. (1981). Readability is a four-letter word. Journal of Business Communication, 18(4), 23-34. doi: 10. $1177 / 002194368101800403$

Siddharthan, A. (2014). A survey of research on text simplification. ITL-International Journal of Applied Linguistics, 165(2), 259-298. doi: 10.1075/itl.165.2.06sid

Silverman, R. D., Speece, D. L., Harring, J. R., \& Ritchey, K. D. (2013). Fluency has a role in the simple view of reading. Scientific Studies of Reading, 17(2), 108-133. doi: 10.1080/10888438.2011.618153

Sprenger-Charolles, L., Colé, P., Béchennec, D., \& Kipffer-Piquard, A. (2005). French normative data on reading and related skills from EVALEC, a new computerized battery of tests (end Grade 1, Grade 2, Grade 3, and Grade 4). Revue européenne de psychologie appliquée/European Review of Applied Psychology, 55(3), 157-186. doi: 10.1016/j.erap.2004.11.002

Sprenger-Charolles, L., Colé, P., Piquard-Kipffer, A., \& Leloup, G. (2010). EVALEC, Batterie informatisée d'évaluation diagnostique des troubles spécifiques d'apprentissage de la lecture. Ortho-Édition.

Tilstra, J., McMaster, K., Van den Broek, P., Kendeou, P., \& Rapp, D. (2009). Simple but complex: Components of the simple view of reading across grade levels. Journal of Research in Reading, 32(4), 383-401. doi: 10.1111/j.1467-9817.2009.01401.x

Tunmer, W. E., \& Chapman, J. W. (2012). The simple view of reading redux: Vocabulary knowledge and the independent components hypothesis. Journal of Learning Disabilities, 45(5), 453-466. doi: 10.1177/ 0022219411432685

Van Silfhout, G., Evers-Vermeul, J., Mak, W. M., \& Sanders, T. J. M. (2014). Connectives and layout as processing signals: How textual features affect students' processing and text representation. Journal of Educational Psychology, 106(4), 1036-1048. doi: 10.1037/a0036293

Verhoeven, L., \& Van Leeuwe, J. (2008). Prediction of the development of reading comprehension: A longitudinal study. Applied Cognitive Psychology: The Official Journal of the Society for Applied Research in Memory and Cognition, 22(3), 407-423. doi: 10.1002/acp.1414

Wauters, L. N., Van Bon, W. H., \& Tellings, A. E. (2006). Reading comprehension of Dutch deaf children. Reading and Writing, 19(1), 49-76. doi: 10.1007/s11145-004-5894-0

Wechsler, D. (2004). The Wechsler intelligence scale for children-fourth edition. London: Pearson Assessment.

Wickham, H., Averick, M., Bryan, J., Chang, W., McGowan, L. D., François, R., Grolemund, G., Hayes, A., Henry, L., Hester, J., Kuhn, M., Pedersen, T. L., Miller, E., Bache, S. M., Müller, K., Ooms, J., Robinson, D., Seidel, D. P., Spinu, V., ... Yutani, H. (2019). "Welcome to the tidyverse." Journal of Open Source Software, 4(43), 1686. doi: 10.21105/joss.01686

Wilkens, R. \& Todirascu, A. (2020). Simplifying Coreference Chains for Dyslexic Children. Proceedings of the $12^{\text {th }}$ International conference on Language Resources and Evaluation for Language Technologies (LREC 2020), Marseille, France.

Ziegler, J. C., Perry, C., \& Zorzi, M. (2019). Modeling the Variability of Developmental Dyslexia. In C. Perfetti, K. Pugh, \& L. Verhoeven (Eds.), Developmental Dyslexia across Languages and Writing Systems (pp. 350-371). Cambridge: Cambridge University Press.

Ziegler, J. C., Perry, C., \& Zorzi, M. (2020). Learning to Read and Dyslexia: From Theory to Intervention Through Personalized Computational Models. Current Directions in Psychological Science, 29(3), 293-300. doi: 10.1177/0963721420915873 


\section{Appendix A}

Example of a normal text and its corresponding simplified version taken from the Alector corpus (Gala et al., 2020a). The Alector corpus is an open-access data database (see https://corpusalector.huma-num.fr/) that allows one to choose a text as a function of different criteria (length, age, type of text, and text difficulty). The texts are available in normal and simplified versions and the comprehension questionnaires are identical for both versions. The whole set is downloadable in pdf.

\begin{tabular}{|c|c|}
\hline \multicolumn{2}{|l|}{ 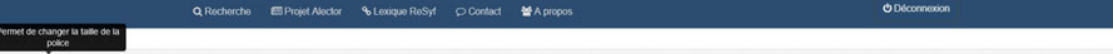 } \\
\hline 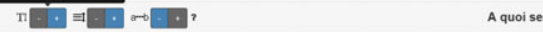 & 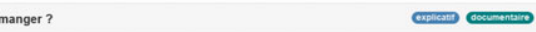 \\
\hline Original (Florence Thinard) & Simplifine (Alector) \\
\hline 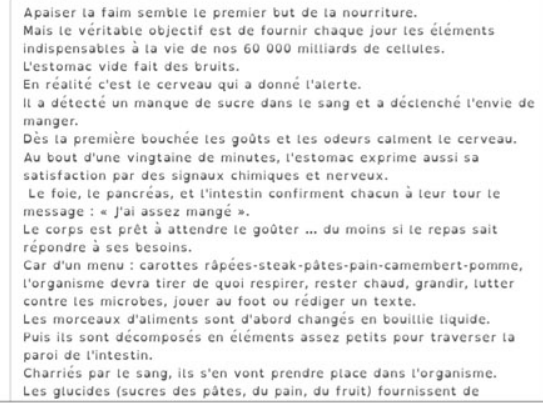 & 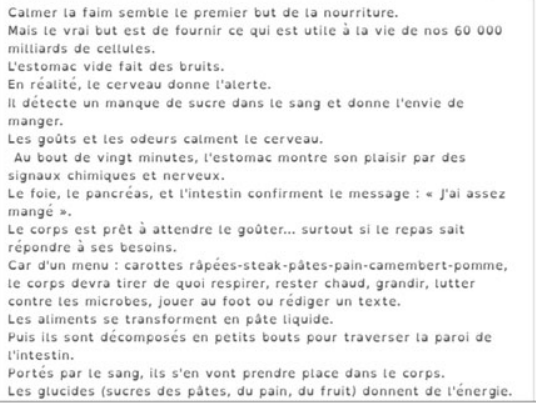 \\
\hline
\end{tabular}

\section{Appendix B Data preprocessing}

Removal of atypical reading times. Raw RTs (sentence reading times; ms) were first transformed to reading times per word (RTW) and reading times per character (RTC) by dividing raw RTs with the associated number of words and number of characters of each sentence. Out of the initial 48,180 RTs (Original and Simplified), we identified those that did not fall into a central tendency, namely RTs that showed were too short. Figure A1 displays the histograms for both the RTWs and RTCs. One can see that the distributions show two tendencies, one count peak on the left side of the histograms and one ex-Gaussian-type pattern on the right side. This dual shape is symptomatic of a dual process, the ex-Gaussian-type RTW values being associated with a regular reading behavior while fast RTWs (typically $<150 \mathrm{~ms}$ ) corresponding to a fast click on the "Next Sentence" button. In our self-paced reading task, this corresponds to a sentence skipping behavior. To eliminate these responses, which caused non-normal distributions, we applied a minimal cutoff of $150 \mathrm{~ms}$ per word (RTW) and $40 \mathrm{~ms}$ per character (RTC). To eliminate exceptionally long responses, we also applied a maximum cutoff of $5000 \mathrm{~ms}$ per word (RTW) and $1000 \mathrm{~ms}$ per character (RTC). This procedure removed 7,212 RTs (14.97\% of the initial dataset).

Removal of outliers. Regular outliers within the ex-Gaussian central tendency were then removed using the interquartile rule: RTWs smaller than Q1 - 1.5* $\mathrm{Q} 3-\mathrm{Q} 1)$ and greater than Q3 + $1.5 *(\mathrm{Q} 3-\mathrm{Q} 1)$ were discarded, Q1 being the first quartile and Q3 the third quartile of the RTW distribution. The interquartile rule removed 2,650 RTWs (5.50\% of the initial number of RTWs).

Text selection. To ensure that we analyzed data only for texts that were properly read, for each child and each text, we only kept texts that had at least $75 \%$ of valid RTWs. This procedure also ensured that questions related to the texts were not randomly answered. Out of an initial number of 3330 texts (20 texts read by 165 participants), this procedure resulted in the selection of 2600 texts for further analysis.

Participant selection. To be included in the statistical analysis, participants had to have at least one valid text per design cell (Original, Simplified) x (Literary, Documentary). This led to the inclusion of 149 participants (out of 165 initially; 9.7\% excluded).

RTW were then $\log 10$ transformed. Figure A2 shows the corresponding histogram. 

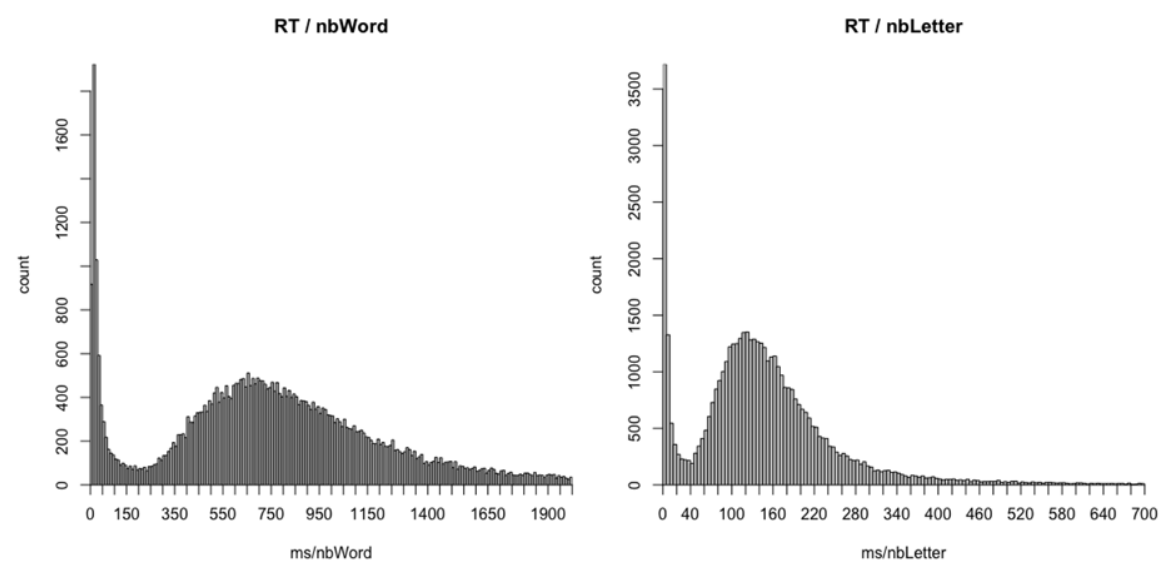

Figure A1. Histograms of response times per word (raw RT divided by the number of words per sentence; left panel) and response times per character (raw RT divided by the number of characters in the sentence; right panel). RTs superior to $2000 \mathrm{~ms}$ per word and $700 \mathrm{~ms}$ per character are not plotted.

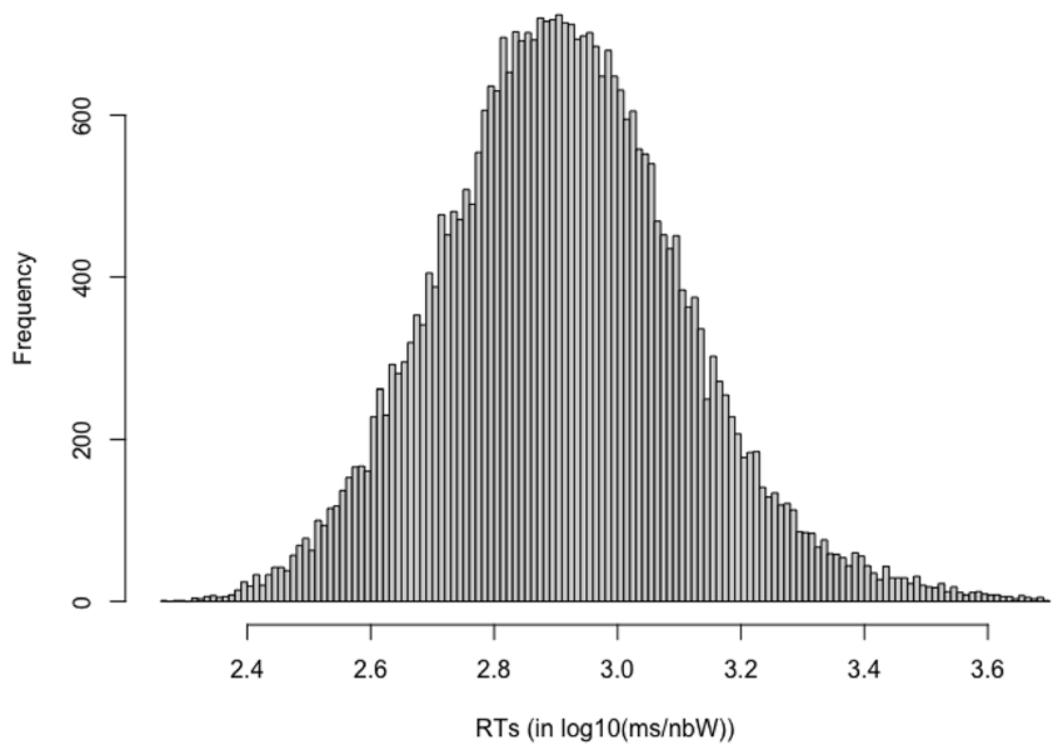

Figure A2. Histogram of the final log10 response time distribution RTs per word (raw RT divided by the number of words of each sentence) after having applied the outlier exclusion and trimming procedure described above.

Cite this article: Javourey-Drevet, L., Dufau, S., François, T., Gala, N., Ginestié, J., and Ziegler, JC. (2022). Simplification of literary and scientific texts to improve reading fluency and comprehension in beginning readers of French. Applied Psycholinguistics 43, 485-512. https://doi.org/10.1017/S014271642100062X 